\title{
Embracing ambiguity ... or not What the Triangle Research Libraries Network learned about collaboration
}

O ne of the most long-lived cooperative groups in the United States, the Triangle Research Libraries Network (TRLN), is a collaborative organization of Duke University, North Carolina Central University, North Carolina State University (NCSU), and the University of North Carolina-Chapel Hill.

Since the 1930s, TRLN members have collaborated to develop complementary collections. As a result, currently 70 percent of the titles held across the consortium are unique to a single institution. Expedited document delivery, direct borrowing, and collective electronic resource agreements encourage users at each institution to view all TRLN library collections as their own. Until recently, however, a key piece was missing: a TRLN-wide catalog. In the 1980s, TRLN had developed the rst online consortial catalog, BIS, ${ }^{1}$ but, in the early 1990s, the libraries moved to a vended system; and by 2004, we were running three different integrated library systems.

In 2006, TRLN undertook a strategic planning process and articulated an overarching vision, Digital TRLN. The vision was to design and create a digital knowledge and research environment characterized by services and tools that facilitate access to large, multifaceted, print and electronic collections. The TRLN Council of Directors explicitly agreed to embrace ambiguity in our new endeavor, and to take bold steps toward our goals. A cornerstone of this initiative would 11 in the missing union catalog piece using modern search technology.

The Endeca software that NCSU had successfully implemented in 2006 was licensed for TRLN and, in early 2008, Search TRLN was launched, featuring faceted searching and browsing, enhanced content, and request functionality. That went well, didn t it? Indeed. But we learned a few things about collaboration and ambiguity in the process.

\section{Relationships matter}

Ann Okerson notes that to succeed a consortium must comprise members who trust each other and know each other well enough to take advantage of cooperation. ${ }^{2}$ The fact that TRLN has such a long history of successful collaboration is a tribute to its sustained, strong, and committed leadership. The provosts of each institution sit on the TRLN Governing Board, and, as a result, TRLN has a high pro le within each institution as a model of longstanding, successful interinstitutional collaboration. TRLN s Council of Directors, and its Executive Committee, meet regularly to oversee initiatives. Standing committees, task groups, and TRLN staff carry out the ongoing work.

While the decision to purchase the Endeca software was made at the highest level of the organization, the library directors recognized that we were embarking on a deep collaboration that had not existed for many years. There was full realization of the complexity of both the technology and the coordinated decision making that would be required. At lower levels, the project drew on relation-

Kristin Antelman is associate director for the Digital Library at North Carolina State University Libraries, e-mail: kristin_antelman@ncsu.edu, and Mona Couts is director of the Triangle Research Libraries Network, e-mail: mona@trln.org

๑ 2009 Kristin Antelman and Mona Couts 
ships built through years of TRLN-sponsored training and development events that bring staff together, familiarizing them both with each other and with the distinct cultures of each library.

\section{A good elevator speech}

In his excellent article on collaboration, Consortia and Their Discontents, Tom Peters cautions how the idea and reality of collaboration can get out of whack. ${ }^{3}$ This can stem from how effectively the initial goal is articulated, but also how it evolves through many meetings between players with their own objectives. Search TRLN was fortunate to have a clear and simple goal, embodied in the project s name. And, given NCSU s recent experience with the Endeca software, the roadmap to success could be envisioned.

So, where $s$ the ambiguity? Recalling the broader Digital TRLN vision, from the outset of this project there were also implicit goals. It was clear that the Search TRLN project was building a shared platform. For what, exactly, was yet to be de ned.

\section{A sense of urgency}

Also helpful in syncing idea and reality is a shared, ongoing sense of urgency. Each library planned to use this platform for its local catalogs. The fact that this project paved the way by doing much of that work certainly inspired a sense of urgency. And it is never hard to nd passionate stakeholders in the catalog. The not-insigni cant upfront nancial investment in software, technical consultation, and time-limited project staff also played a part in motivating us to keep the project meeting its targets.

\section{"Us" and "me"}

In The Lone Ranger is Dead: Success Today Demands Collaboration, Betsy Wilson points to the need for collaborators to change their perspective from me to us. ${ }^{4}$ To a certain extent, Search TRLN was able to dodge this. A fortuitous aspect of the project was that each institution was able focus on both us and me. While the us was the consortial catalog, the me was the local skin, a locally scoped view to the catalog. The local skins (each of which looks quite different than Search TRLN!) served more than once as a safety valve in disagreements about the TRLN interface: when anyone felt they were making a concession, the local skin could stand as the shining model of perfection yet to come.

\section{More risk ...}

We knew that successful collaborators should assume shared (and roughly equal) risk, and risk was certainly present in this project. First, everyone had to buy into the idea of outsourcing the hosting of their catalog to a network service provider in the Triangle. This was a requirement of the technical architecture, but also served to level both risk and responsibility. The project did introduce quite a bit of change into day-to-day ILS operations as well, one aspect of which is that the primary administrator of the TRLN application works for the consortium, not any of the member institutions. The exact nature and dimension of this risk will probably not become clear until unanticipated things begin to happen!

\section{... with less control}

Successful collaborators must also sacri ce some autonomy. The libraries had to coordinate on numerous data decisions in order for search and navigation to work and to create a good user experience. A number of these decisions have implications, some well understood and some not so much, for what each institution can do in their local implementations. TRLN history teaches us that collaboration can be most challenging in the area of data coordination, where for good reasons (or not!), each institution employs signi cantly different bibliographic control practices. Again in this case, our path was eased by the nature of the Endeca technology. The shared database is simply an index created from merged catalog data extracts, with each ILS still serving as the authoritative data store. Nevertheless, the degree of future 
autonomy each library will lose was intentionally not deeply explored during the project.

\section{Roles and skills}

Leveraging complementary deep skills within the libraries was critical to meeting the go live date. In part by design, but also happenstance, each library ended up taking the lead role in one area. One focused on the Endeca technical architecture, another on graphic design, another MeSH and NLM, and another on usability testing.

Wilson asks if we can be taught to collaborate. Certainly, collaboration requires both speci c skills and a certain mindset. For example, negotiating, being able to see tradeoffs, and being comfortable sharing control. Collaborators learn how to cross boundaries. Search TRLN involved many players: a steering committee, three task groups (whose chairs sat on the steering committee), and a newly hired project librarian (who fortunately possessed project management and people skills as well as technical skills). With each task group needing to be representative of all institutions, as well as all types of libraries in the consortium, these groups were not small. In retrospect, discussion of or training in the skills needed for successful collaboration would have been bene cial for everybody. It could be said that training in collaboration is training in how to manage if not embrace ambiguity.

\section{Collaboration and ambiguity}

In his book The Ambiguity Advantage: What Great Leaders Are Great At, David Wilkinson explores ambiguity in the context of leadership styles. In the collaborative leadership style, ambiguity is often associated with talk, not much action, and the tendency to listen to all voices equally. ${ }^{5}$ Where the goal is to innovate, and on a tight timeline, the TRLN collaboration drew on a number of characteristics of generative leadership, the highest level of leadership in Wilkinson $s$ framework. Generative leaders are able to set goals and leave the route to achieving them open, yet they understand the difference between a learning situation and a decisionmaking one. ${ }^{6}$

Search TRLN is an example of a successful collaboration in a new area for many libraries, namely, core services. Collaborating on a core service, as opposed to collection development, requires a different kind of staff support, unfamiliar risks and roles, and perhaps a more uncomfortable or at least unfamiliar level of ambiguity. In taking a new and ambitious direction such as Digital TRLN, the consortium was implicitly relying on its strong center of gravity: a long-standing culture of collaboration, not just cooperation, with shared agendas and values. The leaders had con dence that we could accommodate signi cant tensions as the routes to achieving our goals were explored. Indeed, the Search TRLN project relied on TRLN s strong center of gravity to help us survive the centrifugal forces of complex collaborations.

Part of this project was to gure out when to embrace ambiguity and when not to. Peters says that often the best collaborative efforts occur when there is lively disagreement and debate, not consensus ${ }^{7}$ and this project did include some level of con ict. There was one steering committee contingent that wanted the group to delve more deeply into options and one that simply wanted to accept the task group recommendations as is and keep to the implementation timeline. It rapidly became clear that the former path was strewn with too much ambiguity, and so the project took the latter path. Too much ambiguity in the rst phase could have jeopardized not just the timeline but also the whole project.

\section{Our whole world is ambiguous}

Libraries are awash in ambiguity these days, and no more so than in regard to our catalogs. It would be hard to nd an area of academic librarianship now where the status quo was more despised, and the way forward more uncertain. There are at least two dimensions to this, the more obvious one being that, as a profession, we realize that we have poor discovery tools that have not kept pace with either Web search or user expectations. TRLN 
librarians were in agreement that our catalogs were bad, and that what NCSU had in its Endeca catalog was, if not the answer, at least an improvement. The harder challenge is that the very concept of the catalog is in transition. Implementing a next-generation catalog doesn $t$ answer the question, what should a library catalog be anymore?

Still, all one can do is forge ahead, using vision, talent, and enthusiasm for ambiguity to chart a way forward. Ever aware that competition lurks beneath even happy collaborations, we hope and expect competition to thrive through the local skins, and we embrace the challenge of integrating innovation conceived in the individual libraries with innovation conceived centrally. We also realize the imperative to remain exible and not allow ourselves to become wedded to a model of the union catalog that may not make sense much longer.

As we head into phase two and beyond, there are plenty of ideas within TRLN for what content and services belong inside, around, or outside of Search TRLN. And when the time comes to de ne boundaries between TRLN and other catalogs, digital collections, institutional repositories, and the broader world we are as well positioned as we could hope to be as a consortium to move from ambiguity to action, and maybe back again.

\section{Notes}

1. Joe A. Hewitt, The Triangle Research Libraries Network, North Carolina Libraries 42 (Summer 1984).

2. Ann Okerson, Strength in Numbers: Library Consortia in the Electronic Age, IDT Net conference, Paris (2000).

3. Thomas A. Peters, Consortia and Their Discontents, The Journal of Academic Librarianship 29:2 (March 2003).

4. Betsy Wilson, The Lone Ranger is Dead: Success Today Demands Collaboration, CERL News 61:8 (September 2000).

5. David Wilkinson, The Ambiguity Advantage: What Great Leaders are Great At (New York: Palgrave Macmillan), 2006: 36.

6. Ibid., 121.

7. Peters, 113. n

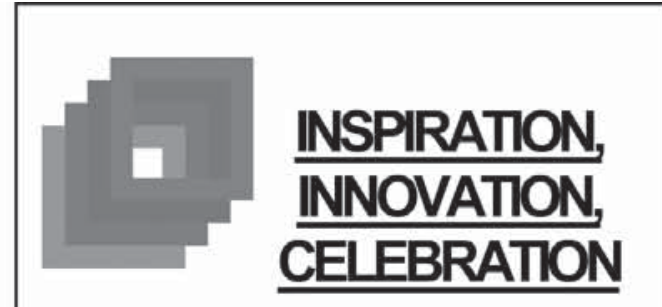

\section{An Entrepreneurial Conference for Librarians June $3 \&$ 4, 2009}

\section{http://zsr.wfu.edu/iic/}

*Learn about and celebrate entrepreneurial accomplishments in libraries.

*Inspire each other to be innovative in our own libraries.

${ }^{*}$ Create a community of interested librarians who will perpetuate the discussion beyond the conference.

Conference to be held in the Elliott University Center at The University of North Carolina at Greensboro

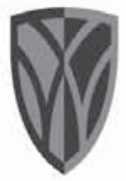
WAKE FOREST U N I V E R S I T Y

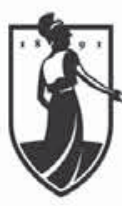
THE UNIVERSITY of NORTH CAROLINA GREENSBORO

University Libraries

Register at http://zsr.wfu.edu/iic/registration or by calling $866-334-2255$ 